\title{
Effect of Tocilizumab on P/F Ratio in Patients with Covid 19 Pneumonia
}

\author{
Wania Rafaey*, Anum Latif, Irfan Ahsan, Hafiza Rafiya Shahid \\ Liaquat National Hospital, Pakistan
}

Submission: February 16, 2021; Published: March 04, 2021

*Corresponding author: Dr. Wania Rafaey, Resident PGY4, Liaquat national hospital karachi, Stadium road karachi, Pakistan

Keywords: COVID-19; Pneumonia; Tocilizumab; Inflammatory cytokines; Dexamethasone

Abbreviation: COVID-19: Coronavirus Disease 2019; SARS-CoV-2: Severe Acute Respiratory Syndrome Coronavirus-2; CRS: Cytokine Release Syndrome

\section{Introduction}

Coronavirus disease 2019 (COVID-19) is caused by severe acute respiratory syndrome coronavirus -2 (SARS-CoV-2). The incubation period of covid-19 is about 14 days with the average of 4 to 5 days from exposure to symptoms onset [1]. The signs and symptoms of covid-19 include fever, dry cough, sore throat, shortness of breath on exertion, myalgia, headache, nasal congestion, diarrhea, loss of taste and loss of smell [2,3]. The severity of illness ranges from mild to critical, mild to moderate disease including mild pneumonia with oxygen saturation ranging from $90-94 \%$ found in $81 \%$, severe disease includes hypoxia or more than $50 \%$ lung involvement on imaging in $14 \%$ and critical disease includes respiratory failure, shock or multi-organ system dysfunction in $5 \%$ of the patients [4].

The mainstay of management of patients with covid-19 is oxygen therapy; it can be given by face mask or nasal cannula [5]. All patients requiring oxygen therapy are also given steroids including dexamethasone or methylprednisolone, $6 \mathrm{mg} /$ day of dexamethasone or $0.5-1 \mathrm{mg} / \mathrm{kg} /$ day of methylprednisolone. Anticoagulation also plays an important role as COVID-19 may be hypercoaguable. Enoxaparin is given in dose of $1 \mathrm{mg} / \mathrm{kg}$ every 12 hourly for 1 to 3 months. One of the main complications of COVID-19 disease is "CYTOKINE RELEASE SYNDROME". Following criteria is applied for CRS.

i. $\quad$ Ferritin $>1000 \mathrm{mcg} / \mathrm{L}$ and rising in last 24 hours.

ii. Ferritin $>2000 \mathrm{mcg} / \mathrm{L}$ in patient requiring high flow oxygen or ventilation. iii. Lymphopenia $<800$ cells/ml, or lymphocyte percentage $<20 \%$ or Neutrophil to lymphocyte ratio of $>5$

a. Ferritin $>700 \mathrm{mcg} / \mathrm{mL}$ and rising in the last 24 hours.

b. $\quad$ LDH $>300$ IU and rising in the last 24 hours.

c. D-Dimer $>1000 \mathrm{ng} / \mathrm{mL}$ (or $>1 \mathrm{mcg} / \mathrm{ml}$ ) and rising in the last 24 hours.

d. $\quad$ CRP $>70 \mathrm{mg} / \mathrm{L}$ (or $>10 \mathrm{hs}$ CRP) and rising in the last 24 hours, in absence of bacterial infection.

e. If any 3 presents on admission no need to document rise and two of the following [6].

Tocilizumab is given to the steroid resistant patients or who present with severe disease in CRS. It is given in the dose of 4 to $8 \mathrm{mg} / \mathrm{kg} \mathrm{IV}$, maximum dose is $800 \mathrm{mg}$. It can be repeated in 12 hours only once. There are few contraindications of Tocilizumab including ALT more than 5 times or bilirubin greater than 2 , sepsis or positive blood cultures, $\mathrm{ANC}<2000$ or thrombocytopenia $<50$, suspected GI perforation, active TB, allergy to Tocilizumab or multiple sclerosis [7]. The aim of the study is to observe effect of Tocilizumab on $\mathrm{P} / \mathrm{F}$ ratio.

\section{Methods}

This is a retrospective study; data was retrieved and analyzed retrospectively from March 2020 to June 2020. 40 patients were included in study. The study was done in Liaquat National Hospital 
Karachi. Patients more than 18 years of age with positive Covid-19 PCR, those with oxygen saturation less than $88 \%$ and those who met the criteria of CRS as described earlier, were included in study. All the patients with age below 18 years, deranged liver function test and proclacitonin value greater than 0.5 were excluded from the study.

\section{Data collection procedure}

Data of the patients meeting the inclusion criteria presented to the Covid ICU/HDU from April 2020 to July 2020 were enrolled in the study. After taking approval from the institutional ethical committee, detailed history documented by researcher including presenting complaints of fever, cough, shortness of breath and altered level of consciousness. Laboratory investigations including CRP, Ferritin, LDH, N/L ratio, IL -6 levels, D-Dimer, P/F ratio will be monitored. Sofa score will be calculated. Patients meeting the inclusion criteria will be given Tocilizumab $(8 \mathrm{mg} / \mathrm{kg}), \mathrm{I} / \mathrm{V}$ and clinical outcome will be assessed as whether patients improved or deteriorated/expired.

\section{Data analysis}

SPSS version 22 will be used for data analysis. Frequencies and percentages will be computed for categorical variables like gender, either one or two doses of Tocilizumab given. Variables will be presented as mean \pm standard deviation for continuous variables like age, $\mathrm{P} / \mathrm{F}$ ratio before and after the administration of Tocilizumab. Chi square will be used to check association between categorical variables while mean comparison will be done by using independent t-test and AVONA as appropriate. P value $<0.05$ will be considered as significant.

\section{Results}

Table 1: Demography.

\begin{tabular}{|c|c|}
\hline Characteristic & N \\
\hline Number of patients & 40 \\
\hline Male & 24 \\
\hline Female & 16 \\
\hline Intubated patients & 17 \\
\hline Non Intubated patients & 23 \\
\hline Age group 20 to 40 & 6 \\
\hline Age group 41 to 60 & 18 \\
\hline Age group $>60$ & 16 \\
\hline
\end{tabular}

(Table 1) In our study total number of patients was 40 and the data was collected retrospectively over a period of four months. 24 patients were males, and 16 patients were females. Out of these 40 patients 17 patients got intubated either at arrival or after few days, 23 were non intubated patients. For our ease we have divided these patients into three groups according to age. Group one consists of patients with age between 20 to 40 years, group two between 41 to 60 years and group three with patients more than 6 years. We have selected the patients for administering the drug Tocilizumab. 8 doses were given to 8 patients and they did not require second dose because either they improved, or they expired. 32 patients were given two doses as shown in (Table2).

Table 2: Drug dosage.

\begin{tabular}{|c|c|}
\hline One dose of tocilizumab & $\mathbf{8}$ \\
\hline Two doses of tocilizumab & 32 \\
\hline Superimposed bacterial infection & 3 \\
\hline
\end{tabular}

30 patients were improved after Tocilizumab. The $\mathrm{P} / \mathrm{F}$ ratio increased, and their clinical condition also improved. 7 unfortunate patients continued to deteriorate even after two doses of the drug. And in 3 patients the $\mathrm{P} / \mathrm{F}$ ratio, clinical condition and need of oxygen remained same. After giving the treatment, 11 out of 17 patients got extubated and total 31 patients showed clinical improvement and reduced oxygen requirement only three patients developed superimposed infection as a complication of drug therapy (Table3).

Table 3: Outcome.

\begin{tabular}{|c|c|}
\hline Outcome After Tocilizumab & N \\
\hline Patients with improved p/f ratio & 30 \\
\hline Patients with further decrease in p/f ratio & 7 \\
\hline P/f ratio un-effected & 11 \\
\hline Patient extubated after Tocilizumab & 31 \\
\hline Clinical improvement & 32 \\
\hline Reduced oxygen requirement & 3 \\
\hline Complication of drug therapy & \\
\hline
\end{tabular}

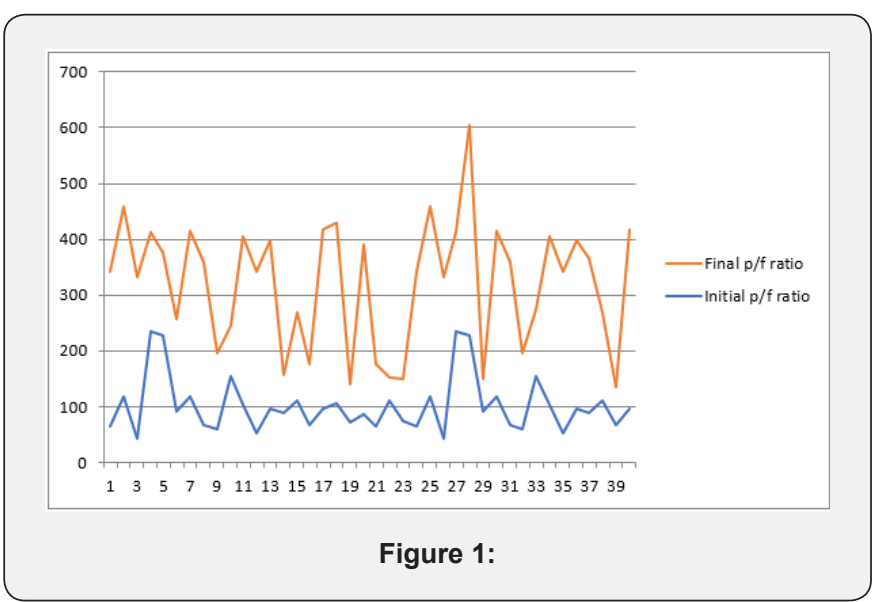

(Figure 1) The above chart showed the comparison between the initial and the final $\mathrm{P} / \mathrm{F}$ ratio of the patients. We can see that majority of the patients responded well to the Tocilizumab drug either with one or two doses. There is also an area of overlap in 
the chart that is representing the deterioration of $\mathrm{P} / \mathrm{F}$ ratio after the drug therapy or no response to the therapy as discussed previously. But majority of the patients responded well, and they had good clinical response.

\section{Discussion}

This study describes the effect of Tocilizumab in the patients with covid-19 that were admitted an Intensive Care unit of a tertiary care hospital. These patients received Tocilizumab as a treatment of covid pneumonia and ARDS. This drug improved the $\mathrm{P} / \mathrm{F}$ ratio of the patients and increases the clinical recovery.

Tocilizumab is a monoclonal antibody that target IL-6 receptors. It is approved by FDA for the treatment of rheumatoid arthritis, giant cell arthritis and juvenile arthritis [8]. Recently it is being used for the cytokine release syndrome in patients with covid-19 pneumonia [9]. As described earlier that CRS is due to release of certain inflammatory cytokines and chemokines [10]. It was observed that patients with Covid-19 pneumonia developed CRS and their timely intubation and starting of Tocilizumab therapy is clinically effective for these patients [11].

Also, some studies suggested the effect of Tocilizumab has a limited role in clinical improvement of patients with CRS. Other case series suggested the significant role of Tocilizumab in treatment of patients with Covid-19 pneumonia [12-14]. In our study we have noticed a significant improvement in clinical response of the majority of patients receiving Tocilizumab. The initial dose is $400 \mathrm{mg}$ and a repeated dose can be given depending on the clinical condition of patient. We have measured the $\mathrm{P} / \mathrm{F}$ ratio before and after the dose of Tocilizumab and we have noticed the improvement of $\mathrm{p} / \mathrm{f}$ ratio and as well as clinical improvement in the majority of patients. The results were better when compared with previous studies $[15,16]$.

In some patient this drug can cause severe superimposed infection [17]. This is one of the major drawback of this therapy. Super imposed infection in these patients halted the recovery and to some extent it increases the mortality rate of the patients. In our study some patient developed superimposed bacterial infection as described in results and they had positive blood culture after giving Tocilizumab therapy. This drug act as two edge sword but the new studies are suggesting the promising role of Tocilizumab therapy in patients of Covid-19 pneumonia with cytokine release syndrome.

\section{Conclusion}

Tocilizumab is an Interleukin receptor blocker. It has a promising role in clinical recovery of the Covid-19 infected patients. It decreases oxygen requirement, improves weaning off from ventilators and also decreases the morbidity.

\section{References}

1. Guan WJ, Ni ZY, Hu Y, WH Liang, CQ Ou, et al. (2020) Clinical Characteristics of Coronavirus Disease 2019 in China. N Engl J Med 382:1708-1720

2. Chen N, Zhou M, Dong X, Jieming Q, Fengyun G, et al. (2020) Epidemiological and clinical characteristics of 99 cases of 2019 novel coronavirus pneumonia in Wuhan, China: a descriptive study. Lancet 395(10223): 507-513.

3. Pan $\mathrm{L}, \mathrm{Mu}$ M, Yang P, Yu S, Runsheng W, et al. (2020) Clinical Characteristics of COVID-19 Patients with Digestive Symptoms in Hubei, China: A Descriptive, Cross-Sectional, Multicenter Study. Am J Gastroenterol 115(5): 766-773.

4. To KK, Tsang OT, Leung WS, Anthony RT, TC Wu, et al. (2020) Temporal profiles of viral load in posterior oropharyngeal saliva samples and serum antibody responses during infection by SARS-CoV-2: an observational cohort study. The Lancet Infectious Diseases 20 (5): 565574.

5. Organization WH (2020) Clinical management of severe acute respiratory infection (SARI) when COVID-19 disease is suspected: Interim guidance $\mathrm{V} 1.2$.

6. Guidelines for Government Employees and ... - covid.gov.pk. The Ministry acknowledges the contribution of Dr. Saira Kanwal, Dr. Kashif Hussain, and HSA/ HPSIU/ NIH team to compile these guidelines. References 1. Disinfection and Sterilization: An Overview. Rutala, William A et al., American Journal of Infection Control 2013, 41:5, S2S52.

7. https://www.nih.org.pk/wp-content/uploads/2020/03/COVID-19NAP-V2-13-March-2020.pdf

8. Kaur S, Bansal Y, Kumar R, Bansal G (2020) A panoramic review of IL-6: Structure, pathophysiological roles and inhibitors. Bioorg Med Chem 28(5): 115327.

9. Le RQ Li L, Yuan W, Stacy SS, Lei N, et al. (2018) FDA Approval Summary: Tocilizumab for Treatment of Chimeric Antigen Receptor T Cell-Induced Severe or Life-Threatening Cytokine Release Syndrome. Oncologist 23(8): 943-947.

10. Lee DW, Gardner R, Porter DL, Chrystal UL, Nabil A, et al. (2014) Current concepts in the diagnosis and management of cytokine release syndrome. Blood 124(2): 188-195

11. Liu B, Li M, Zhou Z, Guan X, Xiang Y (2020) Can we use interleukin-6 (IL-6) blockade for coronavirus disease 2019 (COVID-19)-induced cytokine release syndrome (CRS)? J Autoimmun 111: 102452.

12. Luo P, Liu Y, Qiu L, Liu X, Liu D, et al. (2020) Tocilizumab treatment in COVID-19: A single center experience. J Med Virol 92(7): 814-818.

13. Sciascia S, Aprà F, Baffa A, Simone B, Daniela B, et al. (2020) Pilot prospective open, single-arm multicentre study on off-label use of tocilizumab in severe patients with COVID-19. Clin Exp Rheumatol 38(3): 529-532.

14. Xu X, Han M, Li T, Wei S, Dongsheng W, et al. (2020) Effective treatment of severe COVID-19 patients with tocilizumab. Proc Natl Acad Sci U S A 117(20): 10970-10975.

15. Y Shang, X Yang, Y Yu, J Xu, H Shu, et al. (2020) Clinical course and outcomes of critically ill patients with SARS-CoV-2 pneumonia in Wuhan, China: a single-centered, retrospective, observational study. The Lancet Respiratory Medicine 8(5): 475-481.

16. Martins Filho PR, Tavares CSS, Santos VS (2020) Factors associated with mortality in patients with COVID-19. A quantitative evidence synthesis of clinical and laboratory data. Eur J Intern Med 76: 97-99.

17. Pawar A, Desai RJ, Solomon DH, Adrian JSO, Sara G, et al. (2019) Risk of serious infections in tocilizumab versus other biologic drugs in 
patients with rheumatoid arthritis: A multidatabase cohort study Annals of the Rheumatic Diseases 78(4): 456-464.

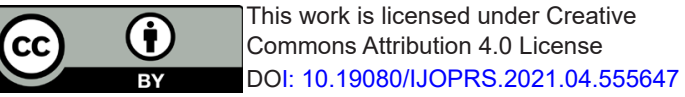

Your next submission with Juniper Publishers will reach you the below assets

- Quality Editorial service

- Swift Peer Review

- Reprints availability

- E-prints Service

- Manuscript Podcast for convenient understanding

- Global attainment for your research

- Manuscript accessibility in different formats ( Pdf, E-pub, Full Text, Audio)

- Unceasing customer service

Track the below URL for one-step submission https://juniperpublishers.com/online-submission.php 